\author{
RITA EDER
}

\title{
Helen Escobedo (1934-2010)
}

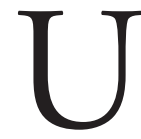

NA Fotografía de Helen Escobedo, envuelta en un rebozo rojo de tono apagado que parece un manto, deja ver su sonrisa aún traviesa; su mirada, detrás de unos finos espejuelos, es inteligente y sabia. Con su empaque y vitalidad parecía muy lejos de la muerte que no tardaría en llegar (fig. I). Unos meses después, con un mensaje inusual que denotaba humor y cierta melancolía, anunciaba a sus amigos que haría un viaje hacia lo azul y sin equipaje. "Lo único que lamento — decía en su despedida - es no haber logrado terminar mis proyectos." Su vida fue un continuum de propuestas que pudo llevar a cabo en diversos campos artísticos e institucionales. Su carisma, generosidad y diversos talentos le permitieron desarrollarse como escultora, dibujante, museóloga y actriz, además de políglota e internacionalista. Poseía el don de saber dirigir instituciones con criterios novedosos y una mano firme fundada en el conocimiento, en el trabajo en equipo, ajena a toda arrogancia.

Nacida en 1934 de padre mexicano y madre inglesa, Helen tuvo la suerte de ser alentada desde muy joven en toda experimentación artística que deseó emprender. A la temprana edad de is años comenzó su educación artística en el Mexico City College donde tomó clases con Germán Cueto, un escultor excepcional en el ambiente mexicano de los ańos cincuenta. Cueto — lejos del academicismo prevaleciente en el medio de la escultura mexicana de entonces - trabajaba el metal desde su formación cubista con lo cual conseguía introducir un nuevo sentido de la fisonomía y la construcción del volumen a base de tiras de metal donde lo hueco y lo ausente eran expresivos y se relacionaban en forma orgánica con el espacio. Trasladaba al campo de la enseñanza 


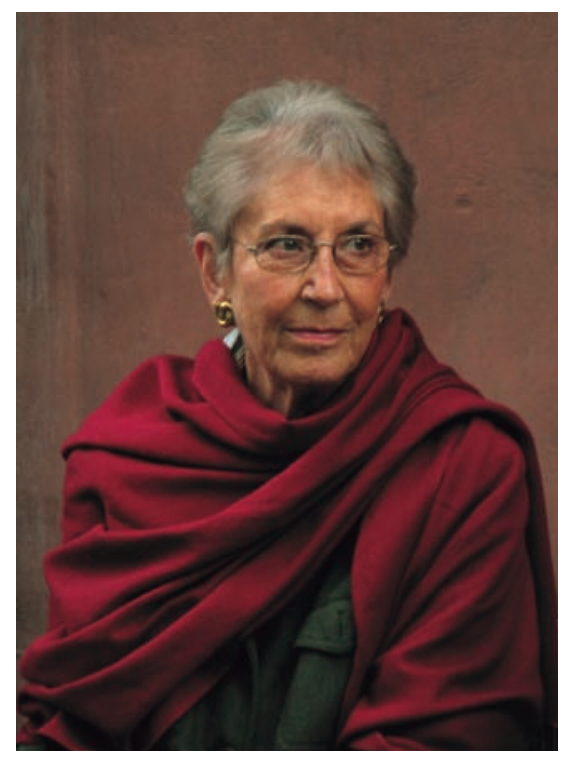

I. Helen Escobedo. Foto: Rosa Irela Vázquez.

de la escultura la libertad y el sentido experimental que caracteriza su obra, de tal manera que el alumno pudiera desarrollar su propia intuición sobre las propiedades del material, el modelado y el espacio. Helen pasó cerca de dos años con el maestro, en los cuales éste le enseñó su técnica de polvo de asbesto y mármol, cómo preparar piroxilina con recetas caseras y la manera de utilizar el alambrón para fabricar el esqueleto de las formas y luego solidificarlas con gruesas pastas. Poco después ingresó al Royal College of Art en Londres (donde permaneció tres años), que le ofreció entrenamiento técnico, estímulo intelectual y contacto con figuras como Epstein, Zadkine y Henry Moore.

A su regreso a México en 1954, Helen expuso con Inés Amor sus figuras expresionistas y orgánicas con gran éxito de crítica y de mercado, pero no fue sino hasta 1964 cuando se operó un cambio radical en su obra, el cual tiene su genealogía en la exposición denominada Vernissage (“inauguración”) (fig. 2). Para realizar su proyecto formó grupos escultóricos en los que aparecen el público, la crítica, el artista posando frente al cuadro, los turistas que entran a la exposición, los amigos que la apoyan y la aceptan. Hay también algunos elementos constructivos como muros y techos, que la artista utilizará más adelante. Las figuras de Vernissage están apenas modeladas: chorreadas las peque- 


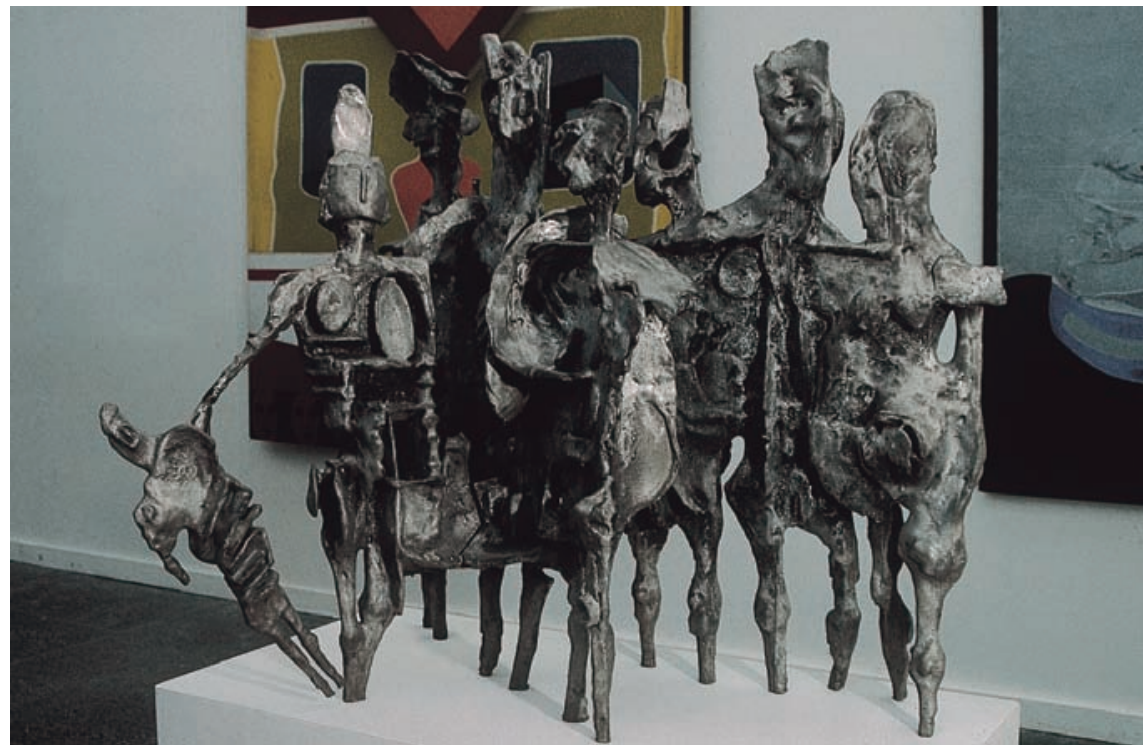

2. Helen Escobedo, Gran paseo, de la serie Vernissage, aluminio, 1964. Exposición México 68, muca. Foto: Eumelia Hernández, 1998. Colección de la artista. Archivo Fotográfico IIE-Unam. D.R. CHelen Escobedo/somaAp/MÉXICO/20II.

ñas cabezas y las extremidades, los cuerpos hacen que todo el conjunto se vea inacabado. Vernissage fue una obra profética; anunció un alejamiento de la profesión de escultora de galería, ya que Helen empezó a trabajar en superficies bidimensionales y monumentales que de suyo planteaban una problemática distinta: liberarse de la base y hacer escultura para integrarla a la arquitectura. Poco después vendrán sus esculturas habitables: formas laberínticas, paisajes lunares que contienen espacios utópicos para ser habitados; estas formas se complementarán con objetos escultóricos funcionales como lámparas, regaderas, radios, muros para incrustar televisiones. Este experimentar en distintos aspectos de la escultura la condujo hacia una especie de integralismo en el que incluyó el diseño, la escultura monumental, la arquitectura y el arte efímero. Más que piezas, inició la invención de sistemas; necesitó todo un conjunto de elementos fuera de la obra, que le darían validez.

Otro cambio radical en su obra fueron los Muros dinámicos de 1968 que ella misma definió de la siguiente manera: 
Mi intención es que mis esculturas no existan como obras de arte, sino que se puedan fabricar en serie a cualquier dimensión y en los colores necesarios. Pueden servir como elementos decorativos, como muros estructurales o como juguetes.

De más de dos metros de altura, los Muros dinámicos incorporan materiales livianos, como madera comprimida policromada con lacas automotrices, varillas de aluminio y el espejo de plástico llamado mylar. Estas estructuras tienen diversos significados: son escultura y muro, biombo o puerta, separan el espacio, pero sus oquedades, transparencias o formas abiertas fungen como unificadores del mismo. Los diez muros de la serie son distintos entre sí y tienen relación con los objetos híbridos, mezcla de pintura y escultura que formaron parte de la invención minimalista y que un purista de la pintura como Clement Greenberg atacó con violencia, ya que amenazaban a la profesión del artista profesional con un perfil específico. Las formas planas, las curvilíneas y las letras no sólo aparecen pintadas, sino que en ellas se inscriben los juegos y ritmos del arte óptico y las anchas bandas del hard edge.

Ambiente gráfico es otro muro dinámico que expuso en Middleheim y que hoy se encuentra en el Museo Universitario Arte Contemporáneo (MUAC) (fig. 3). Se trata de una estructura laqueada en hierro y policromada. Helen la consideró, a pesar de su peso, apenas una maqueta de escultura ambiental. El impacto más fuerte para ella en los tardíos años sesenta fue trabajar con Mathias Goeritz en la Ruta de la amistad. Para ese novedoso planteamiento de escultura pública realizó Puertas al viento, un muro esbelto, horadado por un círculo con prolongaciones rectas y levemente inclinado. Señales, una obra realizada para Auckland, Nueva Zelanda, avanzará en esa misma línea de pensamiento a la que se sumará la relación entre forma, espacio y percepción. Señales consiste en cuatro estructuras de is metros de altura, realizadas en aluminio a manera de escaleras, pintadas en colores vivos, que permiten el paso del aire y desde lejos producen efectos visuales afines a las obras cinéticas por el ritmo de los efectos cromáticos. Después vinieron los Efímeros resueltos con materiales muy ligeros, tubos de cartón, espejos de mylar, muselina blanca y pintura. Éstos consisten en corredores y pasadizos desmontables por los que el público transita y algunas veces es el público mismo quien construye las obras bajo la propia organización de la artista (fig. 4).

Uno de sus primeros Efímeros lo realizó para un simposio de escultura en Nueva Orléans. Helen escogió un corredor natural de pinos para integrar un pasillo con columnas blancas, por el cual podía deambular el público. Esta 


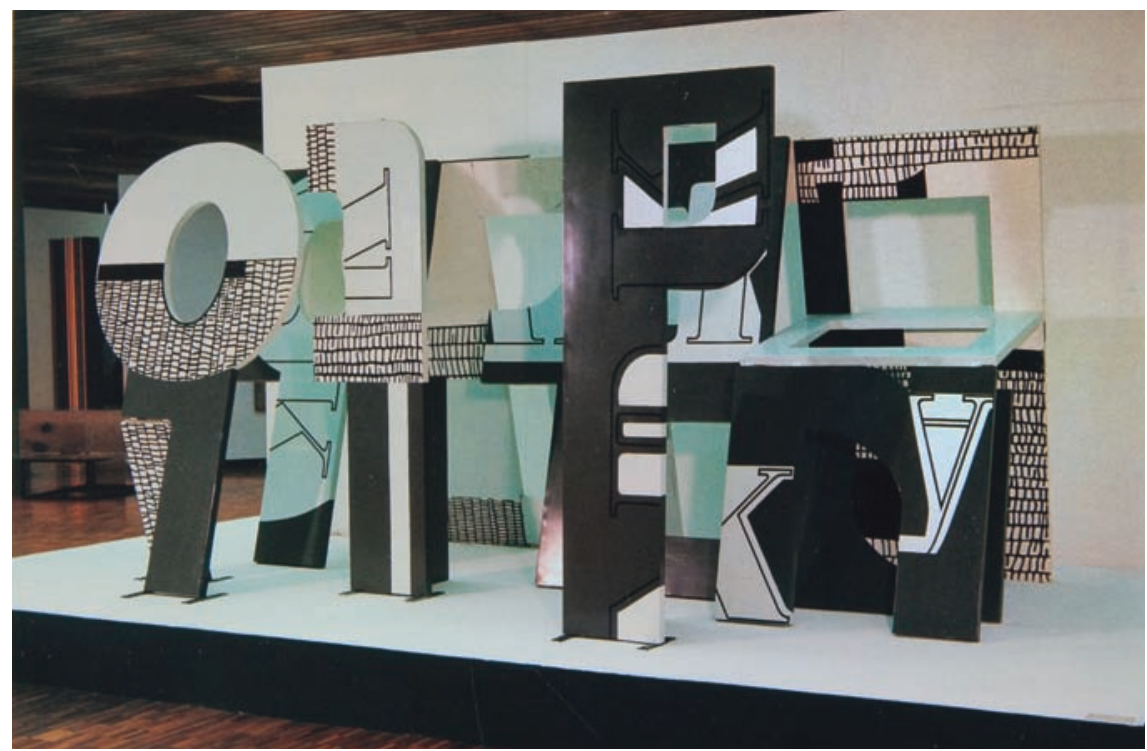

3. Helen Escobedo, Ambiente gráfico, de la serie Muros dinámicos, I. $80 \times 4 \times 2 \mathrm{~m}$, hierro laqueado, 1970. Colección del Museo de Arte Moderno (MUAC). Foto de la artista, tomada de Graciela Schmilchuk, Helen Escobedo. Pasos en la arena, México, Consejo Nacional para la Cultura y las Artes-Difusión Cultural/Universidad Nacional Autónoma de México-DGe/ Turner, 200I, p. 68. D.R. CHelen Escobedo/somaAp/MÉXICo/20II.

escultura transitable era más una propuesta que una obra y sería el antecedente del Efímero que realizó poco después para el Museo de Arte Moderno (МАм) a principios de los años setenta y que fue reproducido - por su carácter innovador- en la exposición La era de la discrepancia, que abrió en el Museo Universitario de Ciencias y Artes (MUCA) en 2007. Este Efímero era también un corredor hecho de tiras de triplay colocadas en semicírculo, con pequeñas separaciones por donde entraba la luz; un espejo en el interior del pasadizo creaba la ilusión de un espacio infinito.

En la trayectoria de Helen aparecen tres características significativas: pensar la escultura desde una nueva materialidad, sujetar esta última a una idea de estructura seriada y el desinterés por crear un estilo reconocible. "Me considero — dirá - una solucionadora de problemas", si bien de problemas que suscita la escultura; de todas formas introducía un principio de funcionalidad en la obra en oposición al formalismo triunfante de la pintura estadounidense 


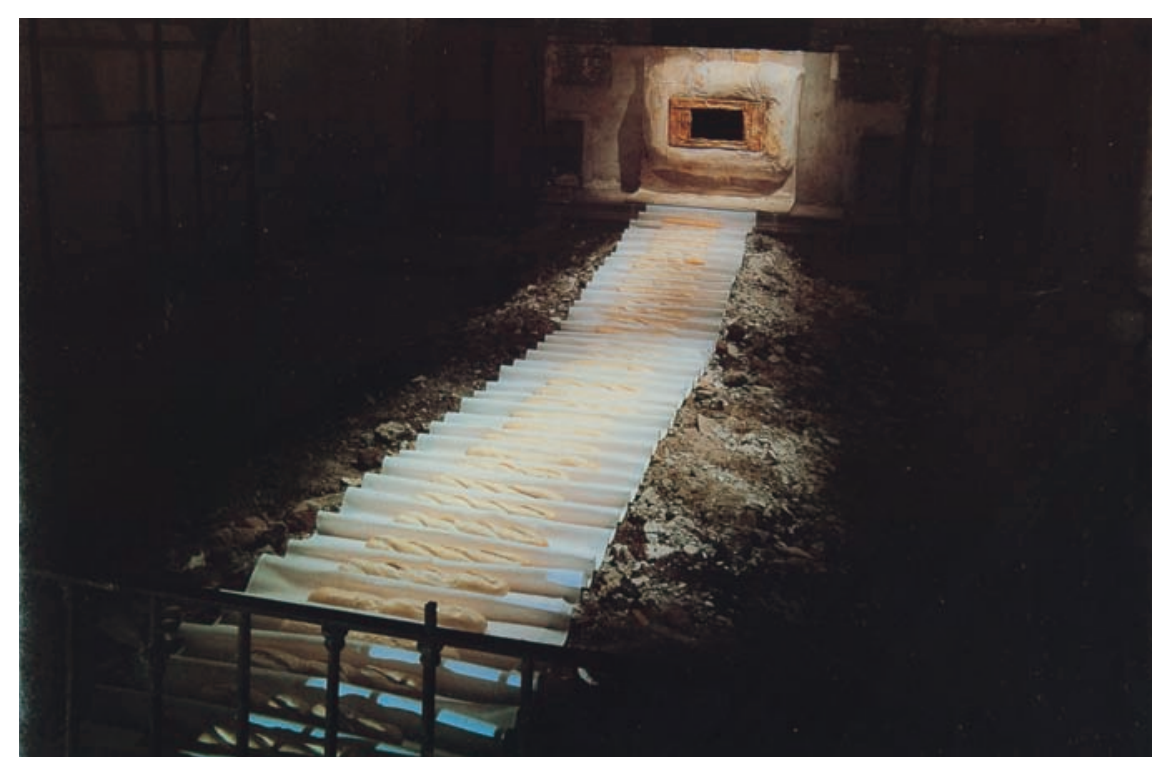

4. Helen Escobedo, Danos el pan nuestro de cada día, de la serie Efímeros, 1993, instalación en el ex convento de Santa Teresa, ciudad de México, tomado de Graciela Schmilchuk, Helen Escobedo. Pasos en la arena, México, Consejo Nacional para la Cultura y las ArtesDifusión Cultural/Universidad Nacional Autónoma de México-DGE/Turner, 200I, p. 227. D.R. (CHelen Escobedo/sOMAap/MÉXICO/20I I.

de los años cincuenta e inicio de los sesenta. Así, su particular concepción del funcionalismo la convierte en escultora, arquitecta y diseñadora que se concibe a sí misma como una experimentadora constante.

La palabra experimentación en arte se usa muchas veces erróneamente; hay quienes piensan que experimentar es producir novedades. En realidad, el término experimentar, que proviene de la ciencia, intenta realizar una operación para establecer alguna verdad, principio o efecto. Experimentar implica abocarse a la solución de un problema; en este sentido, la huella repetida del artista desaparece, pues cada situación exige una respuesta distinta.

Su gusto y su capacidad para trabajar en equipo vino por la vía de un nuevo proyecto artístico impulsado por la Universidad Nacional Autónoma de México (UNAM) a finales de la década de 1970: el Espacio escultórico. Esta obra de diversas implicaciones respondía a un nuevo mecenazgo, el cual decía adiós al 


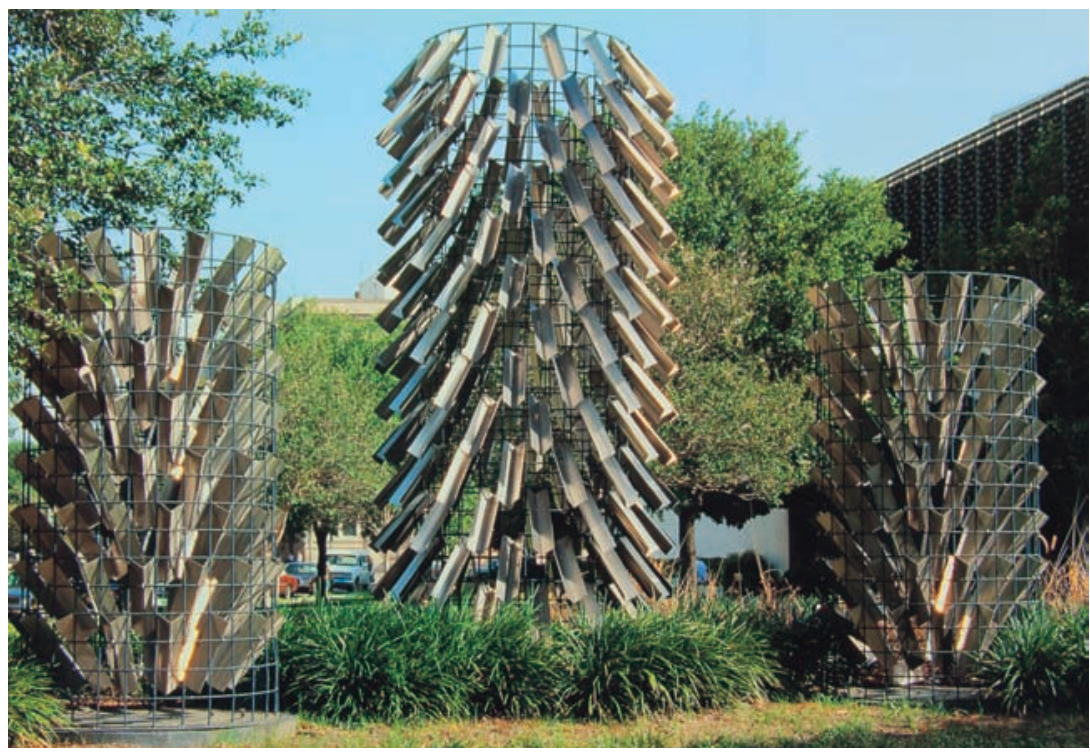

5. Helen Escobedo, Torres de lluvia, 1986. Realizadas para el Simposio de Escultura en Nueva Orléans y ahora ubicadas en el centro de dicha ciudad. Foto de la artista, tomada de Graciela Schmilchuk, Helen Escobedo. Pasos en la arena, México, Consejo Nacional para la Cultura y las Artes-Difusión Cultural/Universidad Nacional Autónoma de México-DGe/Turner, 200I, pp. 62 y 63. D.R. CHelen Escobedo/somaAp/ MÉXICO/2OII.

lenguaje figurativo que pobló la primera etapa de Ciudad Universitaria en los años cincuenta. Se impulsaba el lenguaje abstracto y una propuesta conceptual ecológica o de land-art (fig. 5). El resultado fue una mezcla entre sugerencias arquitectónicas construidas a la manera de una escultura monumental abstracta con cierto sentido de lo primigenio — quizá las formas estilizadas de aire prehispánico-, inscrita en un espacio real, que puede ser recorrida y cuya importancia reside en poner de relieve lo espacial sobre lo visual. La historia de cómo se concibió la solución de esta obra, que puede calificarse de dramática por la oposición radical entre formas naturales rugosas — una explosión de lava- y formas primarias expresivas, aún debe ser revisada. Lo cierto es que fue acogida con regocijo por los estudiantes como un espacio cargado de simbología new age y como una escultura más bien apropiable o espacio social que abarca un concepto más amplio que el de ser transitable. 
Sobre las instalaciones puede decirse que fueron un campo en el que Helen se inició en los años sesenta cuando impartía talleres a estudiantes en universidades de los Estados Unidos y alguna vez en tándem con destacados amigos del gremio, como Marta Palau. En estas ocasiones intervenía diferentes espacios con formas y objetos y trabajaba con cuerdas y cartón para crear ambientes efímeros. En el medio de la instalación se abría aún más su deseo de plantear problemas sociales de variada índole y ahí pulsaban los asuntos más urgentes del mundo global, como la ecología y el tema de la frontera y las migraciones (fig. 6). Si bien su educación artística se inició en el conocimiento profundo del oficio, Helen pudo desprenderse de ello para encontrar un modo propio de hacer y ubicarse en el río del arte contemporáneo que en su etapa globaliza$\mathrm{da}$ es transdisciplinario en sus materiales y en su interés por los planteos de una geografía que produce nuevos mapas, con novedosas rutas y contactos hasta su desenlace en una nueva antropología. La manera del arte contemporáneo de hacer política consiste en encarnarla por medio de propuestas y conceptos que provienen de la filosofía contemporánea. En su trabajo sobre los migrantes, Helen abordó la imposibilidad de sociedades homogéneas como una realidad del mundo actual, así como las contradicciones que esto implica.

Recuerdo muy bien las discusiones que sostuvimos sobre el estilo, no como problema teórico sino como huella o marca reconocible del artista. A Helen, sin previas declaraciones retóricas, le interesó hacer del arte un conjunto de estrategias simbólicas en torno a problemas sociales o a situaciones subjetivas. Para ella el arte se presentaba como un campo de problemas, no como un método crítico; deseaba ser una artista preparada para resolver propuestas y situaciones, tenía otra forma de articular un lenguaje político y de aproximarse a lo utópico desde el humor y cierta subversión de los objetos y las formas.

Desde el punto de vista de la articulación o diálogo con la vanguardia internacional, Helen trabajó con el antisentido o el contrasentido, pero también manifestó cierta preocupación por corregir las nociones de diseño integral de la Bauhaus y quizá por eso era renuente a la definición de la forma y se afanaba por mantener una distancia respecto del diseño integral. En cambio, imaginó y construyó arquitecturas domésticas que fueran realmente funcionales y cuya premisa era estar consciente del espacio privado y no fluido que permitiese compartir la vida. Desde otra perspectiva, se propuso elaborar diseños integrales que no adoptaran la ortodoxia del lenguaje geométrico. Quizá la noción de obra en un sitio específico aguardaba un medio ideal para desarrollar sus habilidades y proyectos. La idea de instalación le permitió aportar un sentido de 


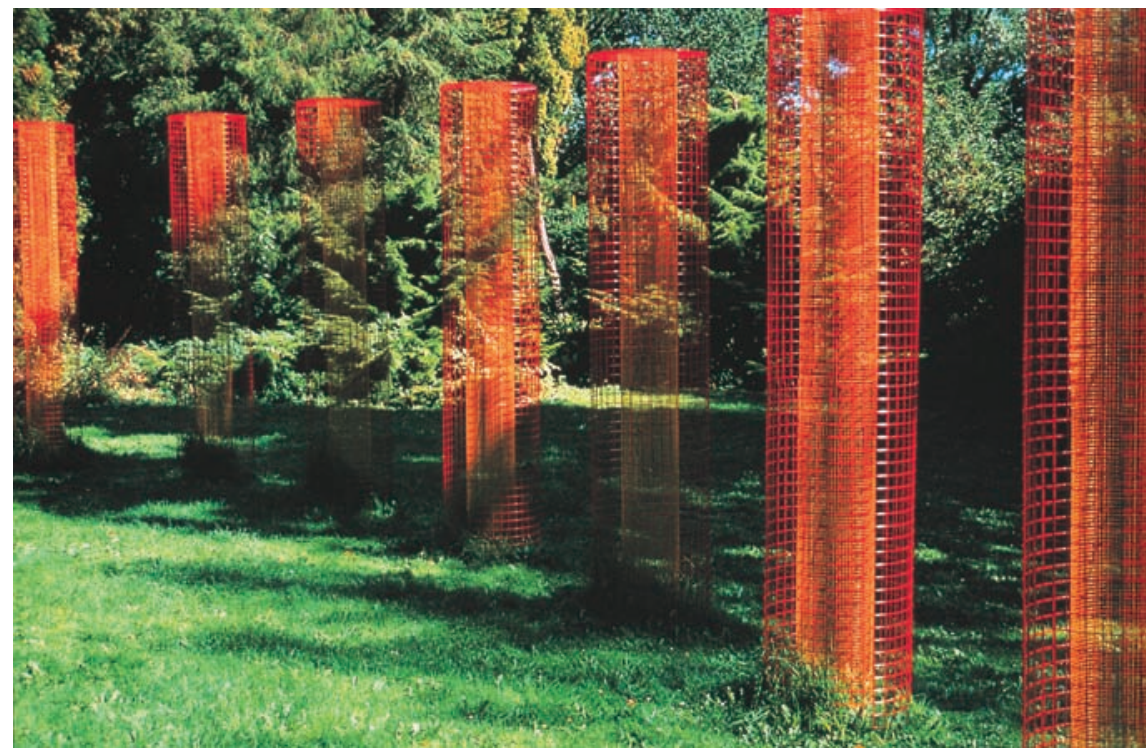

6. Helen Escobedo, Gentle interferences (Leves interferencias), I983, tomada de Graciela Schmilchuk, Helen Escobedo. Pasos en la arena, México, Consejo Nacional para la Cultura y las Artes-Difusión Cultural/Universidad Nacional Autónoma de México-Dge/Turner, 200I, p. I80. D.R. CHelen Escobedo/sOMAap/MÉXICO/20II.

ironía a los problemas ecológicos y sociales. Trabajó sobre la destrucción de la naturaleza por fuego, del medio ambiente urbano por la inundación de basura, así como sobre la extinción de especies de la biodiversidad, por ejemplo de las tortugas y las ballenas. La frontera fue también tema de algunas propuestas entre irónicas y lúdicas de resistencia, como sus objetos de tecnología antitecnológica, primaria y orgánica para lanzar catapultas "al otro lado", precisamente en Playas de Tijuana, justo enfrente de la antigua muralla de metal que cae sobre el mar y fija la línea divisoria entre México y los Estados Unidos. Así lo hizo en la segunda edición de inSite, en 1994, con la propuesta By the night tide o Junto a la marea nocturna. Sus trabajos sobre migrantes en Europa y sus diversas muertes se concentraron en el cuerpo como bulto y caída, como materia fracturada, algo así como el exilio y el espejo roto. En su obra, lo lúdico y lo trágico se entrelazan como en los magníficos dibujos utópicos en los que propone alternativas al paisaje urbano. Convierte lo extraño en parte de un vocabulario con el que convivió bien y utilizó objetos encontrados como las sillas 
y los paraguas. Para hacer sus propuestas, a veces recurrió a la dimensión existencial y trágica del cuerpo, mientras que por otro lado su acercamiento a la abstracción geométrica terminó por destacar lo orgánico. La masa se convierte en filigrana cuando la integra a la naturaleza y apenas introduce algunos aspectos arquitectónicos transparentes; como bien ha observado Graciela Schmilchuk en su libro Pasos en la arena, existe un claro propósito de desmaterializar la intervención en jardines y bosques e intentar que las obras se fuguen de su sitio. Los polos que producen tensiones en su trabajo tienen que ver con su atracción por el humor y el trabajo fino casi inmaterial y lo que veía en el paisaje urbano de México.

Se ocupó no sólo de hacer sus proyectos que manifiestan una vena crítica en torno a la escultura pública en México, también coordinó un libro sobre los monumentos en México y junto con Paolo Gori y Gianni Capitanni emprendió una larga excursión por toda la república en la que sacaron fotos de las esculturas y, entre ellas, de las múltiples cabezas que se encuentran de Cuauhtémoc, Hidalgo, Morelos y Juárez, entre otros. Jorge Hernández Campos llamó a este fenómeno cabezotismo —en su contribución a Monumentos mexicanos. De las estatuas de sal y piedra (publicado por Grijalbo, cuya primera edición en inglés se titula Mexican Monuments: Strange Encounters)—, en donde analiza más a fondo la identificación de los hombres en el poder con ciertos héroes según el modo como intentaban ser percibidos. Otros no necesitaban proyectarse, eran retratos o monumentos de sí mismos, como el que se mandó hacer Carlos Hank González en el Estado de México. Entre los monumentos oficiales y los populares quedó un libro que permite ver la huella y la experiencia de la artista frente a la cultura oficial y el auténtico interés por lo popular. Helen fue, si no pionera, sí contemporánea de la primera hora en la deconstrucción de la escultura al servicio de los anhelos de eternidad del sistema político mexicano moderno.

Un aspecto fundamental de la vida de Helen fueron los museos que dirigió. En ellos logró transponer sus dotes de artista como solucionadora de problemas, su talento para las relaciones humanas, su reflexión sobre lo contemporáneo en el arte y su comprensión profunda de lo espacial. En el MUCA, que dirigió de 1961 a 1978 (primero en calidad de jefa de artes plásticas y después como directora de museos y galerías de la UNAM), pudo hacer una labor de carácter internacional. La lista de exposiciones que organizó es impresionante: desde muestras de arte contemporáneo hasta arte africano y precolombino, sin faltar el arte de China y de otros lugares. Su labor al frente de este espacio uni- 
versitario coincidió con años de cambio para el arte mexicano; ahí desarrolló una actividad que puso a la Dirección de Artes Visuales de la UnAm a la vanguardia en el sentido más inmediato de la palabra: se convirtió en un espacio difusor de proyectos vitales y de encuentro para el arte moderno mexicano e internacional. Este museo se caracterizó por ser uno de los espacios más dinámicos e inéditos para el arte contemporáneo en México que ofrecía alternativas a la política cultural oficial, especialmente después del movimiento estudiantil de 1968.

Helen fue pieza fundamental de la organización de los salones independientes, ya que algunas de sus ediciones se realizaron en ese espacio universitario. El si (Salón Independiente), como se conoce a estas exposiciones, fue lugar de escisión respecto de las políticas culturales del Estado, lo que apresuró el proceso de formación de un arte contemporáneo más extendido entre las nuevas generaciones en México que, para entrar a la contemporaneidad, quizá debían disentir y oponerse a las políticas culturales oficiales.

En el MUCA, y bajo la responsabilidad de Helen, se efectuaron dos ediciones del Salón Independiente; el de 197I fue especialmente memorable por sus propuestas conceptuales, todas realizadas en papel periódico. Pienso que más allá de que los fondos escaseaban para sufragar otras posibilidades, se trataba de una toma de posición. Para Helen fue una oportunidad más para trabajar con materiales cotidianos y accesibles, una manera de explorar la otra cara de su formación clásica en el Royal College of Art en el Londres de mediados de la década de los años cincuenta.

En el espacio de este museo, Helen impulsó trabajos interdisciplinarios de artistas jóvenes, interesados en romper las barreras de los géneros artísticos y en conectarse con el público mediante propuestas relevantes a situaciones de emergencia política. También trajo el performance y el arte conceptual que causó cierta polémica en los periódicos, pero ella, siempre informada y consciente de lo que hacía, supo defender con argumentos la misión de un museo universitario pensado para un público joven.

En los i 8 meses previos a su muerte, algunos amigos le propusimos un proyecto: recrear el trabajo que realizó como directora del Museo de Arte Moderno entre 1982 y I984. Ella no sólo aceptó, sino que participó con entusiasmo en este configurar la memoria de esos años. Fue una experiencia compleja en la que midió diferencias entre un museo del Estado y el museo universitario al que dedicó muchos años de su vida. Lo importante de su paso por el MAM fue desarrollar varias ideas, por ejemplo, el parque de esculturas contemporáneas, 
y organizar el museo de tal forma que estuviera presente el arte moderno y se subrayaran los cambios de materialidad, espacialidad y significación que portaba lo contemporáneo en el arte. Ahí se trabajó en equipo y puede decirse que se produjeron cambios radicales en la presentación del arte contemporáneo y en las estrategias para lograr un público consciente y participativo de acuerdo con la deconstrucción del museo como el lugar de las obras maestras para un público determinado.

Algunos la llamaron nómada. De México a Londres en su primera juventud, luego en Suecia por un par de años y después compartirá su vida y su quehacer artístico entre México y Alemania. Creo que de todas maneras el nomadismo estaba en ella con los viajes o sin ellos. Pero más bien pienso en su cosmopolitismo, su libertad de moverse de un medio a otro y de cruzar culturas y entrar en ambientes distintos, su dominio de varios idiomas y su capacidad para transitar de un medio artístico a otro, como el teatro, el dibujo, la escultura y el trabajo en equipo.

Helen quería integrar su trabajo a la calle y a la naturaleza, involucrarse con la problemática ecológica y ser una diseñadora integral, lo cual haría que la ambientación primero y la instalación después fuesen los medios en que se sentiría más a gusto. Es cierto, como ha escrito Jorge Reynoso Pohlenz, que los motivos de Helen se gestaban en el agitado acontecer de una vida cotidiana como la que llevó: muchos viajes y aeropuertos, culturas distintas, atracción por lo popular en sus diversos aspectos, desde los objetos artesanales hasta el bricolaje de los mecánicos que construyen otros automóviles hechos de pedacería, y el cruce de disciplinas en que la artista podría ser dibujante, pintora, escultora, arquitecta y diseñadora, además de lectora y músico.

Tengo muy presente cómo y dónde conocí a Helen. Era 1975 y estábamos en un lugar de insólita belleza y significación cultural. Nos hicimos amigas en La Quemada, un sitio cerca de Zacatecas identificado por algunos con Chicomoztoc, a su vez un lugar legendario considerado un desarrollo independiente y capital de todos los grupos indígenas asentados al norte del río Grande de Santiago. Esa excursión formaba parte del programa del Primer Coloquio Internacional de Historia del Arte del Instituto de Investigaciones Estéticas bajo la dirección de Jorge Alberto Manrique, quien por su prestigio intelectual había logrado congregar, además de investigadores del propio instituto, a artistas y críticos de México, América Latina y Europa, como Juan Acha y Kazuya Sakai, que llevaban la sección de arte de la revista Plural en los tiempos en que Octavio Paz la dirigía. Ahí estaban, además de Helen, Manuel Fel- 
guérez, Marta Traba, Ida Rodríguez, Edmundo O’Gorman, Mario Pedrosa, Adelaida de Juan, Michel Ragón y muchos más. En lo alto de La Quemada, mientras descansábamos del empinado ascenso, Helen me hizo notar mejor la espacialidad del lugar y el paisaje y comentó sus ideas sobre un arte integral conectado tanto con lo urbano como con la naturaleza. La recuerdo como si la tuviera delante: las manos elocuentes, una cabeza de rizos negros rodeados de una cinta de colores, los ojos encantados mientras veía el paisaje y cierta picardía cuando volvía a la conversación para ponerse en la tierra. Siempre pensé que lo que la hacía artista era su sensibilidad para el cambio y la antisolemnidad.

Pasamos juntas mucho tiempo en su estudio de San Jerónimo. Era una excelsa dibujante y sus proyectos utópicos e instalaciones estaban en esas imágenes a lápiz y en sus collages que introducían muchas veces un objeto subversivo. La noción de proyecto y una elegante patada a la muerte con la que se despide de sus muchos amigos estuvieron presentes en su hora final, y decidió irse de este mundo con su humor siempre fino y elocuente, dueña de su vida por encima de la adversidad; un legado para reflexionar. \$s 